Please do not remove this page

RMIT

UNIVERSITY

\title{
Topic Management in Police-Suspect Interviewing
}

Heydon, Georgina

https://researchrepository.rmit.edu.au/esploro/outputs/9921863348901341/filesAndLinks?institution=61RMIT_INST\&index=null

Heydon, G. (2018). Topic Management in Police-Suspect Interviewing. In Handbook of Communication in the Legal Sphere (pp. 201-218). Walter De Gruyter.

https://researchrepository.rmit.edu.au/discovery/fulldisplay/alma9921863348901341/61RMIT_INST:Resea rchRepository

Document Version: Published Version

Repository homepage: https://researchrepository.rmit.edu.au

(C) 2018 Walter de Gruyter Inc., Boston/Berlin

Downloaded On 2023/04/26 20:22:32 +1000 


\section{Topic management in police-suspect interviewing}

\section{Introduction}

Over the last three decades, a significant shift has occurred in the field of police interviewing mainly led by the police authorities in England and Wales who have sought to address deficiencies in interviewing practice by developing training programs based on empirical research findings (Baldwin 1993; Bull \& Milne 2004; Clarke \& Milne 2001; Moston, Stephenson \& Williamson 1992; Pearse \& Gudjonsson 1996). Although this might seem unremarkable for scholars accustomed to working with client agencies in education, medicine, marketing and a range of other fields, the move towards research-based training for police interviewers in the UK, Australia, New Zealand and now many other parts of the world demonstrates a recognition that interviewing is teachable skill - something that was not widely accepted by police prior to the mid-1980s. Until the introduction of tape recorders into police interview rooms following the UK Police and Criminal Evidence Act in 1984, police interviewing was regarded as either a natural talent, or a skill best acquired on the job, through an ad hoc apprentice-like model (Griffiths and Milne 2005: 167). However, with the sudden availability of masses of recorded interviews to police management, British psychologists were engaged to undertake large-scale surveys of interview data and identify improvements that could be addressed by research-based training materials (Baldwin 1993; Pearse \& Gudjonsson 1996). Although the international research supporting interviewing has been dominated over the past two decades by the discipline of psychology, recently a number of studies focusing on the language of police interviewing have demonstrated the valuable contributions to be made by forensic linguists (Cotterill 2001; Edwards 2006; Haworth 2013; Heydon 2005; Johnson 2008; Rock 2007).

The basis for the evidence-based police interviewing model developed initially in the UK, and now more widely applied, is the Cognitive Interview (Geiselman, Fisher, MacKinnon \& Holland 1986). The information gathering and questioning phases of this model commonly utilise structured conversation to facilitate an "account" from an interviewee. This "Account phase" (see note (1) below) consists of selected topics or subjects addressed chronologically or thematically and generally introduced by the interviewer after an initial "free" disclosure by the interviewee.

This structure is based on proven psychological principles associated with concepts such as memory, rapport and questioning. While originally intended for interviewing eyewitnesses (Clarke and Milne 2001), the cognitive interview model also 
known as the PEACE model ${ }^{1}$ has proven equally effective as the basis for police interviews with suspects. An established model for cognitive interviews with suspects is the Conversation Management model (Shepherd 2007) where the Account phase with structured questioning is supplemented with evidentiary questions and challenges to the suspect's account. Further developments of the model have included sophisticated techniques for uncovering deception, such as the Strategic Use of Evidence (Vrij, Granhag, Mann \& Leal 2011). All of these models of interviewing are broadly termed "investigative interviewing", emphasizing the focus on information gathering rather than the elicitation of a confession.

Investigative interviewing models dominate training programs in the UK, Australia and New Zealand, and are being developed and tested for police forces around the world, from Mozambique to Indonesia. However, another prominent model of interviewing, the Reid Method (Senese \& John E. Reid and Associates. 2005), is used mainly in North America and has also generated significant research interest especially in behavioural psychology. There are a number of critical features that separate the Reid Method from the investigative interviewing approach, the most obvious of which is the emphasis on obtaining a confession and the focus on credibility assessment, or lie detection. In general, the Reid Method advocates a coercive approach through its "nine step interrogation" technique and includes practices that would render the evidence inadmissible in some jurisdictions (e.g. Australia), such as the use of deception to persuade a suspect to confess. The use of the Reid Method is not without controversy (Snook, Eastwood, Stinson, Tedeschini \& House 2010), but its critics are in a weakened position empirically because complete police interviews are not recorded electronically in most jurisdictions where the method is used. ${ }^{2}$ It is notable that it was the introduction of recorded police interviews following the Police and Criminal Evidence Act in the UK that led to significant changes to police interviewing practices there.

Nonetheless, it is still relevant to our discussion to encompass the interviewing practices of North American police officers since many of the underlying techniques and requirements are the same. For example, building rapport and eliciting high quality, detailed narratives are both identified in the Reid Method as important goals for an interviewer. While there might not be the same concerns about voluntariness and the admissibility of evidence produced by the suspect or witness, the reliability of the information is still vital to a successful investigation. With this in mind, we

1 The PEACE model is named for a mnemonic referring to the five main phases of the investigative interview: Planning \& Preparation; Engage and Explain; Account; Closing; Evaluation. It has been the standard model of witness interviewing in England and Wales since it was first introduced in 1992. (See Central Planning and Training Unit 1992.)

2 Usually a recording device is used to capture just the confession following what might be several hours, or even days, of interviewing and interrogation. 
will now turn to the central concern of this chapter, which is the development and management of topics in police interviews.

\section{Topics in police interviews}

As the basic cognitive interview model has developed, police and academic researchers have begun to recognize that subject or topic coverage within an interview is a complex process (see most recently Walsh \& Bull 2015). Topics might include items that constitute direct evidence, such as things that an interviewee heard, saw or did in the immediate vicinity of an incident. However, topics covered in an interview might also include information that an interviewee holds, but which is not direct evidence, for example knowledge of friends or associates of a murder victim, or where witnesses sought for an investigation may be found. Notably, the product of an interview will almost always comprise both evidence that might become part of the courtroom trial (Heffer, Rock \& Conley 2013), and other information or intelligence that will be used to further the investigation. Therefore, the planning and structuring of an interview is now a complex task where the issue of chronology must be combined with a division of evidence/intelligence.

Given the complexity of the interview structure, and the inclusion of two distinct types of subject matter - direct evidence and indirect information or intelligence - it is incumbent upon police investigators to find some way to navigate the various subjects that might be covered in an interview. This is not simply a matter of working through a list of items relevant to the offence: some subjects might be introduced during the Account that are not on the police agenda at all, but which cannot be dismissed as irrelevant without further investigation. Some subjects might be known to the investigator but assume greater relevance and priority in light of other disclosures made by the interviewee. In short, the interview is dynamic, and a good interviewer must be responsive and adaptable to topic shifts, whenever they occur.

This chapter aims to unpack the structure of interviews from a linguistic perspective and demonstrate that choosing the right strategy when changing the topic in a conversation can:

a) have a dramatic impact on the rapport between interactants;

b) affect the capacity of interviewees to volunteer reliable information; and

c) affect the admissibility of evidence.

Rapport has been repeatedly identified as a critical factor in the success of an interview (Collins, Lincoln \& Frank 2002; Griffiths \& Milne 2006; Vallano \& Compo 2011). Part of being a competent interviewer means being able to build and sustain an appropriate level of rapport over the course of an interview. To some extent, this will be contingent upon the character and mood of the interviewee, as well as the personality of the interviewer. However, the appropriate management of topics is a 
simple way of improving rapport or at the very least, reducing the dominance of the interviewer at the interactional level.

Voluntary confessions are fundamental to a fair trial and a technique that can optimize opportunities for interviewees to freely offer new information, whether evidential or not, is surely worth including in interviewing training. This chapter will demonstrate how the appropriate management of topics can be critical in offering interviewees an opportunity to make a voluntary statement, as well as ensuring that the interview as a whole is less likely to be challenged in court on the grounds of undue pressure being applied to the interviewee. Admissability of interview evidence is a key concern for prosecutors, and is affected by police behaviour and practices in the interview room. Although admissibility has become less of a concern with the introduction of electronic recordings in many jurisdictions, inappropriate interviewing methods and a lack of voluntariness of a suspect's statement continue to result in costly delays in the justice process and undermine procedural fairness and public trust (Dixon 2006; Williams 2000)

In order to describe the structure of an interview, we must first take a nuanced and empirically-based approach to the analysis of conversation as a social activity. Conversation Analysis (CA), an ethnomethodological approach to the analysis of talk between two or more participants, is particularly concerned with the way in which speakers take turns at talk and how different types of utterance are used to achieve social and communicative goals (Levinson 1983; Sacks, Schegloff \& Jefferson 1974). In addition to turn-taking, CA provides a set of tools for analyzing the initiation, maintenance and shift of topics in the turn-by-turn construction of a conversation. It is therefore well-suited to this study of managing subjects in a police interview, especially in light of the implications of the "chain rule" (Frankel 1990), described below.

The following section first describes the general rules of turn-taking before examining the special rules of turn-taking in an interview. This provides the basis for an analysis of topic management, and in particular the strategies that are available to speakers when they want to change or pursue a topic. We can then return to consider the impact of topic management strategies on rapport, voluntariness and admissibility. In the course of this chapter, readers will be introduced to some of the basic terminology of conversation analysis. This can be used to produce a simple schematic for training interviewers in effective and strategic topic management.

\section{Conversation Analysis}

Conversation Analysis (CA) is a method of analyzing talk that describes the rules that speakers apply to regulate interactions, such as being able to determine who will speak next (Sacks et al 1974). This may seem trivial, yet even the briefest of conversations between two or more people is a highly rule-governed social activity requiring split-second timing and the almost instantaneous interpretation of a raft of social 
cues and structures, just to know when to speak and what to say. Analysts working within the CA tradition are able to specify the cues that speakers use to achieve such remarkable levels of cooperation and this research has identified the means by which speakers are able to moderate the timing of speaker change to avoid interruption and (unintended) simultaneous talk. The work of Sacks et al (1974) demonstrates that in multi-party talk, there are rules that govern the passing of the floor amongst the participants and in any interaction there are rules about what kind of turn can follow a previous turn. Clearly, these rules are not inviolate; however, as a set of norms they are powerful and, when broken, require redress to maintain social cohesion - consider the work that is done by participants to manage interruption or simultaneous talk so that social harmony is maintained. We will not discuss the actual rules of turn-taking here, as it is not directly relevant to this analysis, but it is important to note that these rules exist and produce powerful constraints on participants in a conversation.

When Conversation Analysis began to establish the rules of casual conversation, the importance of relevance had already been identified as part of a Cooperative Principle (Grice 1975) that governs interactions between speakers. Using the CA approach to spoken data, Harvey Sacks and his colleagues demonstrated that this is also embedded in conversational structure, and indeed part of being a successful interactant is being able to offer a relevant response, and being able to identify the relevance of another's contribution, through inference if the relevance is not immediately obvious (Sacks 1987). Thus, when one party to a conversation makes an initial contribution (an "initiation" turn), it requires a second contribution (a "response" turn) from another party in order to function properly as part of a successful interaction. And the content and function of this response turn is limited by the initiation: it must be appropriately relevant to the content of the initiation, and it must match the function of the initiation. In other words, each part of this two-part exchange can only make sense if the other part is executed properly by the conversational partner. A question what is the time? - has no function in a conversation if it is not followed by a relevant response - I don't know, three-thirty, time for lunch - or a response that might be made relevant through further clarification - I'm holding a coffee (inference: I can't turn my wrist to see my watch and tell you the time). If there is no response, or no inference can be made that the next turn is an answer to the question, then the question is no longer functioning as a request for information about the time. It may, in some very highly specific set of circumstances, function in some other way, such as an admonition for time-wasting or a philosophical observation, but this would require a lot of inferential work on the part of the interactants, unless that function was somehow more explicitly conveyed. Part of this requirement for relevance is the selection of the appropriate type of turn. A question requires an answer turn in response; an invitation requires an acceptance turn or a declining turn; an accusation requires an admitting turn, or a denial turn; a greeting requires another greeting turn (Bilmes 1988).

Finally, and perhaps most obviously, the order of the two types of turn is also critical to their successful functioning in a conversation. Except in certain television 
quiz shows, ${ }^{3}$ responses must always follow initiations in order to function properly. Thus, initiations are characterized as turns that require a relevant and appropriate type of response in the next turn, and in this way, CA finds that the initiation and the response are two parts of a pair of turns that must occur in a specific order and in close proximity in the conversation. For this reason, such turns are called "adjacency pairs" and they are the building blocks of conversation (Schegloff \& Sacks 1973). In order to understand the importance of these observations, particularly to social harmony, consider the slight that is suffered when one party offers a greeting that is not followed by a reciprocal greeting turn. Questions must be completed with relevant answers, invitations insist upon acceptance or refusal and accusations require a confession or a denial. It is true that other responses are possible to any of these types of initial turns, but this deviation would be noticed by participants and require some explanation - I'll let you know about the party when I've checked my diary.

These general rules of relevance across pairs of turns continue to apply in an interview, and must therefore be observed in order to build social harmony and rapport (cf Heydon 2011). We will return to this aspect of interviewing later, where we will show how police interviewers can use this knowledge to avoid unnecessary and harmful damage to their rapport building efforts as they interact with suspects and witnesses. However, we will first discuss an important difference between interviews and other conversations, which is the rules about who speaks next. In an interview, unlike ordinary conversation, a special rule of turn taking called the chain rule (Frankel 1990) keeps returning the "floor" to the interviewer.

In his analysis of doctor-patient communication, Frankel (1990) identified the special turn-taking rules of an interview in an institutional setting. Sacks et al (1974) had already established that the rules of turn-taking in ordinary conversation allow parties to select the next speaker (including themselves in self-selection) so that potentially any party can take a turn at initiating a new adjacency pair. The important difference between ordinary conversation and an institutional interview is that in the latter, only the professional party has automatic access to initiations. Quite simply, and just as the I'm asking the questions here cliché makes clear, the interviewer is in charge of initiations while the interviewee is confined to responding to these questions (Greatbatch, 1988). That is what makes it an interview. Even when the interviewee does produce an initiation turn, such as a clarification, the floor and the right to produce initiations, returns to the interviewer immediately after that adjacency pair is completed. Thus the following sequence from an interview is typical of this pattern:

3 In the US quiz show Jeopardy, the answer to a question is provided and the contestant supplies the relevant question. However, this is not actually a new turn taking rule per se, as it is in fact an agreed inversion of the accepted norm whereby the quiz master is actually understood to be asking something like: 'If the answer to a question were given as $\mathrm{X}$, what is the question that would have preceded that answer?' 
Excerpt 1 From police interview with a suspect recorded in Victoria, Australia showing insert sequence and application of the chain rule

\begin{tabular}{|c|c|c|c|}
\hline Line & Speaker ID & Turn function & Turn \\
\hline 403. & pio1: & Police question (Q1) & $\begin{array}{l}\text { so you didn't bother saying anything to } \\
\text { them }\end{array}$ \\
\hline 404. & & & that the glass was broken or \\
\hline 405. & IN1: & Suspect question (Q2) & to who \\
\hline 06. & pio1: & Police answer (A2) & to Betty ... in at the store \\
\hline $\begin{array}{l}407 . \\
408 . \\
409 .\end{array}$ & IN1: & Suspect answer (A1) & $\begin{array}{l}\text { no. that happened af- } \\
\text { when I walked out } \\
\text { when I wal- }\end{array}$ \\
\hline 410. & pio1: & Police Question (Q3) & $\begin{array}{l}\text { yeah but you didn't stop to think you'd } \\
\text { go back in }\end{array}$ \\
\hline 411. & & & $\begin{array}{l}\text { and tell them that you've broken their } \\
\text { front door }\end{array}$ \\
\hline 12. & IN1: & Suspect Answer (A3) & [nup] \\
\hline 13. & pio1: & (continues Q3) & or anything \\
\hline 414. & IN1: & (continues A3) & nup. \\
\hline 15. & & & she knew it was broken \\
\hline 16. & & & you could hear it going \\
\hline & & & I heard it ... going. \\
\hline 418 & pio1: & Police Question (Q4) & what was your reason for assaulting Ian. \\
\hline $\begin{array}{l}419 . \\
420 .\end{array}$ & IN1: & Suspect Answer (A4) & $\begin{array}{l}\text { over that phone call } \\
\text { cause that's ... the only place that it } \\
\text { would have came from... }\end{array}$ \\
\hline
\end{tabular}

This pattern of Question 1, Question 2, Answer to 2, Answer to 1 is called an insert sequence (Levinson 1983: 304-305). It does not, as demonstrated in this example, change the default turn-taking rule that allocates initiations to the interviewer and responses to the interviewee. The subsequent turns show that the question initiation turns continue to be allocated to the police interviewer (Q3 and Q4). In this way, the participants create a "chain" of question-answer pairs with a strict regulation of turn type distribution (Frankel 1990; Heydon 2005). This chain rule has extremely important implications for topic management, which we will discuss below.

\section{Topic management in interviews}

We established above that there are specific rules of turn-taking that apply to interviews, and that an important feature of interviews is the default allocation of initiations to the interviewer and responses to the interviewee. This gives interviews their 
characteristic question-answer structure, but it also has important implications for the management of topics by participants. The management of topics in interviews is the main focus of this section.

Topics are introduced by participants to a conversation as a way of contributing new information, or eliciting new information from other speakers. In ordinary conversation, any participant has the potential to introduce a new topic to the conversation, and any other participant can choose to maintain that topic during their turn at talk, or change the topic to a new one. The easiest way to introduce a new topic into a conversation is to use an initiating turn that contains that topic: Did you hear about Bill's new car? The next speaker is then obligated, according to the maxims of cooperation (Grice 1975) to provide a response that is relevant to the topic of that initiation: Sure - everyone's talking about it. Initiations are by far the turn of choice for new topics. To introduce a new topic in a response turn requires a different strategy (Jefferson 1984). First the speaker must respond to the preceding initiation, and only then can they move towards their new topic: Sure, everyone's talking about it. But you know I don't think a new car is the key to happiness - since I started yoga, I think it's all about the mind-body balance. This kind of gradual shift is used by speakers to demonstrate adherence to Grice's maxim of relation, and to maintain a cooperative stance with the first speaker, but still manage to change the topic. Nonetheless, the flexibility of ordinary conversation allows for the next turn to be used by the first speaker to return to his/her topic: Well, you can have your yoga-I reckon a new Porsche would make me pretty happy right now. I hear it handles like a dream.

But interviews do not have this level of flexibility, at least not in their default state. When all the initiations are allocated to the police interviewer by the 'chain rule' (see above), this simultaneously grants the interviewer access to topic changes at almost every turn. At the end of every initiation-response sequence, the application of the chain rule means that the floor by default returns to the interviewer. In this way, the interviewer is provided with another opportunity to start a new topic, with no structural obligation to maintain the relevance of the previous turn, because it was a response. This is not at all like ordinary conversation - in fact if such a pattern were to emerge during a casual conversation, it is likely that the responding party would protest: I feel like I'm being interrogated here!

This raises an important point about topic management and interviewing: the chain rule of interviewing results in topic initiations being unequally distributed in favour of the interviewer. In fact, having only access to response turns, the interviewee is very limited in their capacity to introduce a new topic. Following the discussion above, we can identify two distinct strategies for changing the topic in an interview (or any interaction): the first is a disjunctive topic shift and occurs in initiations when the interviewer introduces a new topic without any reference to, or acknowledgement of, the topic of the previous interviewee turn. The second type of topic shift is a stepwise topic transition which can be employed by interviewees in response turns, just as our hypothetical speaker above moved from the topic of Bill's new car, to the benefits of yoga. 
Analysis of police interview data in Heydon 2005 finds that police officers have a tendency to rely on disjunctive topic shifts as in lines 210 and 212 in the following example:

Excerpt 2 From police interview with a suspect recorded in Victoria, Australia showing stepwise and disjunctive topic shifts

Line Speaker ID Turn function

199. pio7

Police topic initiation

200.

201. SPT7

202. pio7

Suspect topically relevant response

Police topic initiation

203. SPT7

204.

205. pio7

206. SPT7

207. pio7

208. SPT7

209.

210. pio7

211. SPT7

212. pio7

213.

214.

215. SPT7
Turn

right and um when you

purchased that did you ah

believe it to be a certain

substance

yeah yeah //oh-*

what ${ }^{\star}$ did you believe

it to be

well marijuana

it was compressed in

a little block $\mathrm{n}=$

$=$ all right $=$

$=\mathrm{I}$ thought I'd get a

whole lot more than what

I got but

all right

cause I was hoping to have some for Christmas

to tell the truth but hh

now

it's all gone

police in searching your

premises

searched the underneath

of your house

are you aware of that

yeah

In fact, disjunctive topic shifts account for the majority of all topic changes in the interactions that comprise the Account phase of the interviews with adult suspects used for this study. Stepwise topic transitions rarely occur in police interviewer turns, but are frequently found in interviewee turns, which is consistent with the chain rule allocating all the response turns to interviewees. The excerpt above also gives several examples of the suspect using stepwise topic transitions to achieve topic change in the interview, in lines 206, 208 and 211. 
The distribution of topic management tools in this way has important implications for the three key aspects of police interviewing referred to in the Introduction above: rapport building; reliability of intelligence obtained in the interview; and the admissibility of interview evidence. Each of these will be discussed further below.

\section{Discussion}

\subsection{Rapport building}

Disjunctive topic shifts are found by Heydon (2005) to provide a means by which police interviewers can maintain control of the interview content and exclude topics that have been introduced by the suspect through stepwise topic transitions. This level of control over the interview content is found to be unnecessary, especially in light of the structural features of an interview that automatically pass topic control to the interviewer with initiation turn types (Heydon 2005: 174-179). On the contrary, the current PEACE model of interviewing training encourages the interviewer to pass control to the interviewee (Milne \& Bull 1999), although as illustrated above, this is very difficult to achieve because of the chain rule of interviews.

As we found earlier, an arrangement where one party continually asks questions and controls the topic shifts is very dissimilar to ordinary conversation, and this feature of interviews naturally creates a considerable barrier to putting the interviewee at ease. Building rapport in an interview has been shown to be critical to eliciting reliable and detailed accounts (Collins et al. 2002; Griffiths \& Milne 2006; Vallano \& Compo 2011; Walsh \& Bull 2015), so a turn-taking structure that emphasizes the distance between the participants requires some attention.

The use of disjunctive topic shifts in particular is problematic for interviewers who are attempting to build rapport. Interviewers are instructed to be "active listeners" during the Account phase (indeed, at any time that the interviewee is taking a turn at talk), yet there is little in the investigative interviewing literature to suggest what this might entail. There is some mention of the use of receipt markers or feedback to encourage further contributions - uh huh, go on, and then what happened? - and some discussion of behavioural strategies, such as nodding and taking up a synchronous body position, but little about what to do when an interviewee turn ends, as it inevitably must (see for instance Milne \& Bull 1999; Stacey \& Page 2012). Royce (2005: 10) provides a set of active listening instructions for crisis negotiators, drawn from an earlier FBI source, and the verbal and non-verbal acts that are described are consistent with the approaches described more broadly in the UK-based training material as rapport building. However, this specific active listening skills development does not seem quite as far advanced in the investigative interviewing literature as in the crisis negotiation field. 
An understanding of topic change strategies can fill this gap, because taking a new turn and changing topic is essentially the only option left to the interviewer when the interviewee no longer responds to the abovementioned invitations to continue his or her turn. In this situation, our earlier analysis indicates that interviewers tend to rely on disjunctive topic shifts. However, this does not offer the interviewee any acknowledgement of his or her prior turn, and indeed dismisses the value of that turn (Heydon 2005). This may be intentional, as a means to control the allowable contributions by the interviewee, or it may be simply due to carelessness, stress or ignorance of the damage that disjunctive topic shifts might cause to the rapport building process.

The avoidance of disjuncture in topics is taken for granted when we converse with a friend, or conduct a business conversation with colleague or even a stranger. The topic of a participant's prior turn is typically acknowledged before a new topic is initiated, and often a speaker will attempt to make a link between the old topic and their new topic with a stepwise topic transition. This observation offers interviewers two straightforward strategies to manage the change in topics that will eventually occur in any interview:

- acknowledge the content of the interviewee's prior turn; and

- link the upcoming new topic with the interviewee's prior topic.

The first strategy may involve some feedback or a token of acknowledgement, such as thanks for providing so much detail or yes, you mentioned earlier that you were in a hurry to leave. Importantly the language must remain neutral and the interviewer must avoid offering an evaluation of the interviewee's topic.

The second strategy involves more effort, and may be combined with the first. In this instance, the interviewer needs to create a series of stepwise topic transitions to move from the interviewee's topics to the new interviewer topic. This is especially useful when the interviewee wants to backtrack to an earlier interviewee topic: thanks for providing so much detail about the car. You mentioned earlier that when the car arrived you were not in such a good position to see it - can you tell me how you came to get a better view of the car later?

\subsection{Reliability of intelligence}

The use of topic initiations that are interviewee-centered can make an important contribution to maximizing the reliability of information provided by the suspect or witness. As we have seen, the default conversational structure of an interview is one where the interviewer has consistent access to initiations such as questions, which are the most powerful topic management tools. In this way, the normal rules of an interview mean that the interviewer controls the choice of topic. This may be relevant at times during the interview and the strategic introduction of specific subjects may be 
crucial to a successful interview (Shepherd 2007). However, at the start of the Account phase, when the interviewee is invited to give a free narrative, the first priority must be to ensure that the interviewee has exhausted their own subject matter before the interviewer begins to strategically introduce new topics (Milne \& Bull 1999). This avoids contamination of the interviewee's story with police intelligence or priorities, since every police topic change imposes a police agenda on the interviewee's narrative.

In addition, while the interviewee is producing a narrative based on their memories of an event, the accuracy and reliability of their story can be threatened if their cognitive load is increased by a sudden change of topic requiring retrieval of a memory from a different area of the brain (Fisher \& Geiselman 1992; Milne \& Bull 1999). The emphasis on allowing the interviewee to produce a free narrative without interruption from the interviewer is central to the principles of investigative interviewing because of its value in protecting the integrity of the interviewee's story and minimizing disruption of the memory retrieval process.

In terms of topic management, this means that the topic choice must, as far as possible, rest with the suspect or witness in the interview during the free narrative phase, and the probing questions that follow. The police-led topic changes must wait until the interviewer is confident that there are no further topics that the interviewee will introduce spontaneously. This can be quite difficult to establish, especially since interviewees are commonly reluctant to initiate a topic shift, or introduce new material that is not requested. This can apply even when the interviewee is asked repeatedly if they wish to add anything further to the interview, and when they do actually have important new information to contribute, as in the following extract from Heydon (2005):

Excerpt 3 From police interview with a suspect recorded in Victoria, Australia showing reluctance of suspect to introduce new topics, even when explicitly requested by the police interviewer.

$\begin{array}{lll}\text { Line } & \text { Speaker ID } & \text { Turn function } \\ \text { 290. } & \text { Pio2: } & \text { Police Topic }\end{array}$

291.

292. SPT2:

293.

Suspect response

(long silence)

294. pio2: Police request for new information

295. SPT2: $\quad$ Suspect silence, then denial then new topic initiation
Turn

(2.0) so there was (0.6) absolutely no reason

(.) why you should have treated 'er in that manner

(1.0) nup

(12.6) ((soft intermittent paper shuffling sounds during silence)) was there anything else that (.) a:h you wish to add to (0.2) what's happened

(2.8) no:oh jus (2.0) if you wanna

(h)know what

(h)happened y'know 
296.

(.) we- (0.8) we went back

to Littlevillage

297.

(2.0) I didn't have my ke:ys hh

298.

(0.4) um (0.4) to get in (0.8)

to the (.) hotel

299.

so (0.6) we went back to u:m

300.

(0.6) her place in Satellite River

(2.6) talked until (1.8) five

'clock in the morning

As is clear from the example above, the onus falls on the interviewer to permit ample time during the free narrative phase so that interviewees can respond with longer turns that might include stepwise topic transitions. SPT2 here pauses twice for between two and three seconds in line 295 when negotiating a topic shift in order to pick up the thread of his narrative that had earlier been disrupted by a police agenda topic (establishing whether there was a reason for the offence - see line 290). SPT2 also downgrades his own topic initiation - jus (2.0) if you wanna (h)know what (h)happened y'know - which emphasizes his reluctance to take the floor even when explicitly invited to do so.

Permitting the interviewee time to develop their own topics is an important step in handing over control of the interview to the witness or suspect, at least in the elicitation of a free narrative that marks the beginning of the Account phase. In so doing, interviewers reduce the chance that their own questioning, and topic management, might contaminate the interviewee's evidence, because the control of the topics is then largely managed by the interviewee. It also allows interviewees to introduce new material that has not been covered by the interviewer, and might have been otherwise missed, as nearly occurred in the example above.

It is a simple fact that interviewees will struggle to provide information that is not requested unless they have access to resources that allow them to change the topic as they see fit. The stepwise topic transition therefore plays an important role in ensuring that the reliability of evidence is not compromised through omission.

In England and Wales, there is an important corollary to this discussion, and this relates to the caution. Suspects in these jurisdictions are required to "mention when questioned something that you later rely on in court" or risk an adverse inference being drawn by the Court from their failure to disclose such evidence during the interview. However, a suspect may claim that they were not questioned about a specific event or detail that they later rely on for their defence, and so it is incumbent upon investigating officers to ask as many questions as are necessary to cover any of these likely defences. Nonetheless, just as in other jurisdictions that do not have such a caution, the interviewer-led questioning should be conducted after the suspect has exhausted their own topics in relation to the investigation. 


\subsection{Admissibility of evidence}

The extent to which a confession was made voluntarily by a suspect is often tested in court, and an important consideration will be the role of the interviewer in eliciting the confession. As we have seen, topic management provides an important opportunity to differentiate between an interviewer-led interview, and an interview where suspects or witnesses are able to volunteer information. By relying on disjunctive topic shifts in turn initiations, police interviewers run the risk of excluding topics introduced by the interviewee, and dominating the choice of subjects in the interview.

During the elicitation of a confession, a turn structure that favours the interviewee's contributions has obvious advantages. If interviewees are able to execute stepwise topic transitions to introduce new information, and these turn shifts are permitted or even encouraged by the interviewer, it will be easier to show later that any admissions made during the interview were made voluntarily. There will be fewer instances of police assertions being used to elicit an agreement from the suspect, which is a weak form of confession and one that might well be challenged in court by the defence counsel. The statements that make up a confession must be produced by the suspect in his or her own words without any pressure or coercive force from the police interviewer, and the only topic management structure that permits this is one where suspects are able to move in and out of topics as required in order to produce their own admissions. Clearly, if the interview is structured so that topics are managed and changed predominantly by the police interviewer, there is a risk that any admissions will appear to have been suggested or led by the interviewer.

Even at the investigative level, admissions or observations provided by witnesses and suspects alike are more reliable and more easily attributable to the interviewee later if they have been produced in a topic that they themselves have introduced. Where the topics in an interview are entirely managed and introduced by the interviewer, and interviewees are led through the narrative created by the police interviewer, it will be easier for witnesses or suspects to distance themselves from these statements later on the basis that they did not frame the topics or choose the words used to describe the object, person or event.

The management of topics by the participants in an interview can be assessed in post-interview evaluations as a way of identifying weaknesses in the evidence that might arise if the key admissions were made in police-led topics. Thus the analysis of topic management can make an important contribution to both brief preparation and training. This is discussed in more detail below.

\section{Implications for practice}

The discussion above has demonstrated the importance of topic management to three critical aspects of police investigative interviewing: rapport building, reliability 
of the interviewee's account and admissibility of the evidence. Conversation Analysis provides tools that reveal the impact of turn-taking structures on topic management, and demonstrates that interviewees are in a weak position when it comes to changing the topic, compared with the interviewer. While police training materials currently emphasise the need for interviewers to pass control to the interviewee for the free narrative and subsequent probing phases, and to avoid introducing police topics before the interviewee has completely exhausted their own topics, there is little in the literature or interviewing guidelines to suggest how this might be achieved in practice.

This chapter suggests that police might benefit from some instruction in turn-taking structures, and the nature of topic management. The two types of turn transition identified in the CA literature - disjunctive and stepwise - are easily understood when illustrated with examples and provide a framework for officers to manage topics more effectively. The current literature tends to focus on turn-taking phenomena that are more visible to non-specialists, like interruptions, silences or minimal responses, but this is confusing because in fact these turn types are not consistently productive or unproductive. A turn that appears to be an interruption might in fact be evidence of scaffolding that builds a close affinity between speakers; silences that in one context might allow time for an interviewee to gather their thoughts and recall extra details, might in another context be felt by the interviewee as pressure to say anything to fill the gap, no matter how accurate or reliable the information; minimal responses can operate to encourage the interviewee to keep talking but can also indicate that the police interviewer agrees with the interviewee, which is usually entirely inappropriate.

Keeping the training focus on topic management and the different types of topic shift avoids these confusing categories of turn types, and allows police interviewers and trainers to identify successful interviewing strategies more consistently. An evaluation tool like the Griffiths Question Map (Griffiths \& Milne 2006) maps the questions asked by an interviewer according to several broad categories (open, closed, yes/no, leading etc) and then draws conclusions about the efficacy of the interview and the skills of the interviewer according to the pattern of questioning. However, while this has value in assessing the quality of the questioning, the GQM does not reveal anything about the quality of the information produced by the interviewee. At the very least, an evaluation tool that categorized topic initiations could distinguish between police topics and interviewee topics, and in conjunction with the GQM, such an analysis could plot when those initiations occurred in relation to the question types being used by the interviewer. This topic management-based evaluation would capture the extent to which an interviewee had been able to volunteer new information in the course of the interview, and how that particular interviewee responded to specific question types, rather than the GQM outcome, which is only able to assess the interviewer behaviour, and not the interviewee responses. 


\section{Concluding remarks}

This chapter has identified several aspects of topic management that are closely linked to evidence-based investigative interviewing. The importance of applying linguistic analysis to police interviewing within the accepted models (i.e. Cognitive Interviewing and PEACE) is key to the acceptance of new training techniques by police practitioners. A great deal of research already exists demonstrating the efficacy of these models and police agencies are unlikely to be interested in new techniques that are not consistent with existing practice. This is especially true in the United Kingdom, but also in New Zealand, Norway, and increasingly in Australia and Canada and even the United States of America where the Reid Method has dominated practice for several decades. This chapter is intended to demonstrate in part how linguistic analytic tools can indeed enhance and extend these existing models of investigative interviewing training and practice, and in addition, to demonstrate specifically how topic management is a crucially relevant phenomenon that can be used to improve rapport building, as well as the reliability and admissibility of evidence in criminal cases. It seems likely that similar analyses of topic management can also be applied to other legal questioning settings, including mediations, restorative justice conferencing, tribunals, and review boards.

\section{References}

Baldwin, John. 1993. Police interview techniques: establishing truth or proof? The British Journal of Criminology 33(3). 325-352.

Bilmes, Jack. 1988. The concept of preference in conversation analysis. Language in Society 17. 161-181.

Bull, Ray \& Becky Milne. 2004. Attempts to improve the police interviewing of suspects. In G. D. Lassiter (ed.), Interrogations, confessions, and entrapment, 181-196. New York: Kluwer Academic.

Clarke, C. \& R. Milne. 2001. National evaluation of the PEACE investigative interviewing course. Police Research Award Scheme. London: Home Office.

Collins, Roger, Robyn Lincoln, \& Mark G.Frank. 2002. The effect of rapport in forensic interviewing. Psychiatry, Psychology and Law 9(1). 69-78. doi: 10.1375/pplt.2002.9.1.69

Cotterill, Janet. 2001. Domestic discord, rocky relationships: semantic prosodies in representations of marital violence in the 0. J. Simpson trial. Discourse and Society 12(3). 291-312.

Dixon, David. 2006. A window into the interviewing process? The audio-visual recording of police interrogation in New South Wales, Australia. Policing and Society: An International Journal of Research and Policy 16(4). 323-348. doi: 10.1080/10439460600968123

Edwards, Derek. 2006. Facts, norms and dispositions: Practical uses of the modal would in police interrogations. Discourse Studies 8(4). 475-501.

Frankel, Richard. 1990. Talking in interviews: a dispreference for patient-initiated questions in physician-patient encounters. In G. Psathas (ed.), Interaction competence, 231-262. Washington DC: University Press of America. 
Geiselman, R.E., R.P. Fisher, D.P. MacKinnon \& H.L. Holland. 1986. Enhancement of eyewitness memory with the cognitive interview. American Journal of Psychology 99. 385-401.

Greatbatch, David. 1988. A turn-taking system for British news interviews. Language in Society 17. 401-430.

Grice, H.P. 1975. Logic and conversation. In P. Cole \& J. L. Morgan (eds.), Speech acts (Syntax and Semantics Volume III), 41-58. New York: Academic Press.

Griffiths, A. \& R. Milne. 2006. Will it all end in tiers? Police interviews with suspects in Britain. In T. Williamson (ed.), Investigative interviewing : rights, research and regulation, 167-189. Cullompton, UK; Portland, Or.: Willan.

Haworth, K. 2013. Audience design in the police interview: The interactional and judicial consequences of audience orientation. Language in Society 42(1). 45-69. doi: 10.1017/ S0047404512000899

Heffer, Chris, Frances Rock \& John M.Conley. 2013. Legal-lay communication : textual travels in the law. Oxford; New York: Oxford University Press.

Heydon, Georgina. 2005. The language of police interviewing : a critical analysis. New York: Palgrave Macmillan.

Jefferson, Gail. 1984. On stepwise transition from talk about a trouble to inappropriately next-positioned matters. In J. M. Atkinson \& J. Heritage (eds.), Structures of social action: studies in conversation analysis, 191-222. Cambridge: Cambridge University Press.

Johnson, A. J. 2008. Changing stories - Achieving a change of state in suspect and witness knowledge through evaluation in police interviews with suspects and witnesses. Functions of Language 15(1). 84-114. doi: 10.1075/fol.15.1.06joh

Levinson, Stephen C. 1983. Pragmatics. Cambridge: Cambridge University Press.

Milne, Rebecca \& Ray Bull. 1999. Investigative interviewing : psychology and practice. Chichester ; New York: Wiley.

Moston, Stephen, Geoffrey M. Stephenson \& Thomas Williamson. 1992. The effects of case characteristics on suspect behaviour during police questioning. The British Journal of Criminology 32. $23-40$.

Pearse, John \& Gisli H. Gudjonsson. 1996. Police interviewing techniques at two South London police stations. Psychology, Crime \& Law 3. 63-74.

Rock, Frances. 2007. Communicating rights: the language of arrest and detention. Houndmills: Palgrave Macmillan.

Sacks, Harvey. 1987. On the preferences for agreement and contiguity in sequences in conversation. In G. Button \& J. Lee (eds.), Talk and social organisation, 54-69. Clevedon, Philadelphia: Multilingual Matters.

Sacks, Harvey, Emanuel Schegloff \& Gail Jefferson. 1974. A simplest systematics for the organisation of turn-taking for conversation. Language 50(4). 696-735.

Schegloff, Emanuel \& Harvey Sacks. 1973. Opening up closings. Semiotica 8(4). 289-327.

Senese, Louis C. \& John E. Reid and Associates. 2005. Anatomy of interrogation themes : the Reid technique of interviewing and interrogation (1st edn.). Chicago: John E. Reid and Associates.

Shepherd, Eric. 2007. Investigative interviewing : the conversation management approach. Oxford; New York: Oxford University Press.

Snook, B., J. Eastwood, M. Stinson, J. Tedeschini \& J. C. House. 2010. Reforming investigative interviewing in Canada. Canadian Journal of Criminology and Criminal Justice 52(2). 215-229.

Stacey, Harriet \& Alison Page. 2012. Investigative interviewing: a guide for workplace investigators. Canberra City: WISE Workplace.

Vallano, J. P. \& N. S. Compo. 2011. A comfortable witness is a good witness: rapport-building and susceptibility to misinformation in an investigative mock-crime interview. Applied Cognitive Psychology 25(6). 960-970. doi: 10.1002/acp.1789 
Vrij, A., P. A. Granhag, S. Mann \& S. Leal. 2011. Outsmarting the liars: Toward a cognitive lie detection approach. Current Directions in Psychological Science 20(1). 28-32. doi: $10.1177 / 0963721410391245$

Walsh, D. \& R. Bull. 2015. Interviewing suspects: examining the association between skills, questioning, evidence disclosure, and interview outcomes. Psychology Crime \& Law, , 21(7). 661-680. doi: 10.1080/1068316x.2015.1028544

Williams, J. W. 2000. Interrogating justice: A critical analysis of the police interrogation and its role in the criminal justice process. Canadian Journal of Criminology-Revue Canadienne De Criminologie 42(2). 209-240. 